\author{
S.M. Hamdy \\ H.O. Barrada \\ M.S. Fahmy \\ H. Samir
}

\section{Headache associated with transient or permanent cerebrovascular disease}

Received: 18 February 2002

Accepted in revised form: 19 June 2002

S.M. Hamdy $(\varangle) \cdot$ H.O. Barrada

M.S. Fahmy $\bullet$ H. Samir

Department of Neurology,

Kasr El-Aini Faculty of Medicine,

Cairo University,

Clinica 35 Dokki Street,

Giza, Egypt

e-mail: shamdi@mednet3.comed.com.eg

Tel.: +20-2-7041590

Fax: $+20-2-7498750$

\begin{abstract}
Headache is a common symptom in stroke, however the frequency, location, duration and other characteristics of the patients who developed headache during stroke are difficult to define. We studied headache characteristics in patients with first-ever acute stroke (hemorrhagic or ischemic) or transient ischemic attack (TIA) and assessed the relationship between headache, stroke location, and etiology. The study included 104 consecutive patients (mean age $55.8 \pm 0.8$ years; range, 40-70 years) admitted with acute stroke. Eleven patients had TIA, 70 ischemic stroke, and 23
\end{abstract}

hemorrhagic stroke. Headache was reported in 37 patients $(35.6 \%)$ and was more common in hemorrhagic stroke compared to ischemic stroke or TIA $(p<0.05)$. Headache was present in $26.8 \%$ of the patients with anterior circulation stroke and in $62.5 \%$ of the patients with posterior circulation stroke $(p=0.006)$. No relationship was found between the size of the lesion detected by computed tomography and the presence of headache.

Key words Headache • Migraine • Neurophysiological tests • Neuroradiological studies • Stroke

\section{Introduction}

Headache is a common symptom in stroke, however the frequency, location, duration and other characteristics of the patients who develop headache during stroke are difficult to define. Since a prospective design was used only in some of the previous surveys, which produced partly conflicting results [1-6], we decided to study headache features in patients with first-ever acute stroke (hemorrhagic or ischemic) or transient ischemic attack (TIA). In addition, we assessed the relationship between headache, stroke location, and etiology.

\section{Patients and methods}

The study included all consecutive patients admitted to the Neurology Department of the University Hospital, Kasr El-Aini, Cairo for a first-ever acute stroke or TIA over a period of 1 year. We investigated all patients using a standard protocol including demographic characteristics, educational level (illiterate, literate, level of education), occupation (intellectual worker or manual worker), vascular risk factors, previous history of headache, clinical signs and symptoms, electrocardiography, computed tomography (CT), duplex and transcranial Doppler ultrasound, and magnetic resonance imaging and/or angiography in selected cases. Cases involving artery dissections or subarachnoid hemorrhages, and unconscious, confused and/or aphasic patients were not included in the present study. We classified infarcts in the anterior circulation or in the posterior circulation according to the anatomical and vascular locations (anterior in the territory of internal carotid artery and posterior in the vertebrobasilar territory). To detect the severity of headache, the scale proposed by Blanchard and Andrasik [7] was used $(0=$ no headache and $5=$ severe); we considered a score of $1-2$ to represent mild headache while a score $>3$ was moderate or severe headache.

Headache was defined as cephalic pain appearing before or after other stroke symptoms. Headache features studied included the side of the headache (unilateral, unilateral alternating, or bilateral), severity of headache (mild, moderate, or severe), location of headache [diffuse; anterior (frontal, temporal, or parietal); posteri- 
or (occipital)], pain quality (pulsating or stabbing), and accompanying symptoms of headache (nausea, vomiting, photophobia, and phonophobia). "Sentinel headache" was defined as a headache noted by the patient 15 days before stroke onset, and "onset headache" as a headache reported by the patient at stroke onset or on the same day of stroke onset. "Sentinel-onset headache" occurred before and during stroke onset, and "late-onset headache" is that reported by patients 2 or more $(\leq 7)$ days after stroke onset.

We correlated the presence of headache with the size of the lesion on CT scan considering ASPECT criteria, with 7 being the cut-off point [8] because infarct was defined as a visible lesion on CT scan and $<1 \mathrm{~cm}$.

Statistical analysis was carried out by using the chi-squared test and Fisher's exact test when appropriate: $p<0.05$ was considered statistically significant.

\section{Results}

The study included 104 consecutive patients (mean age $55.8 \pm 0.8$ years; range, $40-70$ years) admitted with acute stroke (Table 1). Eleven patients had TIA, 70 ischemic stroke, and 23 hemorrhagic stroke. Headache was reported in 37 patients $(35.6 \%): 15(40.5 \%)$ had sentinel headache (mean time, $7.8 \pm 3.1$ days before stroke onset), 18 had onset headache, 4 had sentinel-onset headache and no patients had late-onset headache. Patients with headache were more likely to be males $(p<0.005)$ and to be intellectual rather than manual workers $(p<0.01)$. Hemorrage was more frequently observed as the pathology of stroke among patients with headache than among headache-free patients $(p<0.05)$, while there was no difference in the distribution of stroke or TIA between the two groups.

Headache was present in $26.8 \%$ of the patients with anterior circulation stroke and in $62.5 \%$ of the patients with posterior circulation stroke $(p=0.006)$. Among the 37 stroke patients with headache, the location of pain was anterior in $45.9 \%$, posterior in $21.6 \%$, and diffuse in $32.4 \%$ (Table 2). Frontal, temporal, or parietal headache was present in $84.2 \%$ of the patients with anterior stroke, whereas occipital headache was present in $85.7 \%$ of the patients with posterior stroke. The low number of the patients with headache did not permit any correlation between the characteristics of the pain and the accompanying symptoms when considering

Table 1 Baseline characteristics of the 104 patients with acute stroke

\begin{tabular}{|c|c|c|c|c|}
\hline \multirow[b]{2}{*}{ Risk factors, n (\%) } & \multicolumn{2}{|c|}{ Headache patients $(\mathrm{n}=37)$} & \multicolumn{2}{|c|}{ Headache-free patients $(n=67)$} \\
\hline & & & & \\
\hline Males & 23 & $(62.2)$ & 22 & $(32.8)^{* * *}$ \\
\hline Age $40-50$ years & 12 & $(32.4)$ & 21 & $(31.3)$ \\
\hline Age $51-60$ years & 16 & $(43.2)$ & 21 & $(31.3)$ \\
\hline Age $61-70$ years & 9 & $(24.3)$ & 25 & $(37.3)$ \\
\hline Hypertension & 28 & $(75.7)$ & 67 & $(100.0)$ \\
\hline Smoking & 10 & $(27.0)$ & 39 & $(58.2)$ \\
\hline Diabetes mellitus & 10 & $(27.0)$ & 32 & $(47.8)$ \\
\hline Alchool use & 2 & $(5.4)$ & 3 & $(4.5)$ \\
\hline Ischemic heart disease & 3 & $(8.1)$ & 10 & $(14.9)$ \\
\hline Hyperlipidemia & 10 & $(27.0)$ & 29 & $(43.3)$ \\
\hline History of headache & 16 & $(43.2)$ & 14 & $(20.9)$ \\
\hline \multicolumn{5}{|l|}{ Pathology, n (\%) } \\
\hline Ischemic stroke & 23 & $(62.2)$ & 47 & $(70.1)$ \\
\hline Transient ischemic stroke & 2 & $(5.4)$ & 9 & (13.4) \\
\hline Hemorrhage & 12 & $(32.4)$ & 11 & $(16.4)^{*}$ \\
\hline \multicolumn{5}{|l|}{ Socio-economic status, n (\%) } \\
\hline llliterate & 22 & $(59.5)$ & 42 & $(62.7)$ \\
\hline Literate & 4 & $(10.8)$ & 9 & (13.4) \\
\hline \multicolumn{5}{|l|}{ Educational level } \\
\hline Primary school & 3 & $(8.1)$ & 4 & (5.9) \\
\hline Secondary school & 4 & $(10.8)$ & 11 & $(16.4)$ \\
\hline University grduate & 4 & (10.8) & 1 & $(1.5)$ \\
\hline \multicolumn{5}{|l|}{ Occupation } \\
\hline lntellectual worker & 14 & $(37.8)$ & 11 & $(16.4)^{* *}$ \\
\hline Manual worker & 23 & $(62.2)$ & 56 & $(83.6)$ \\
\hline
\end{tabular}

$* p<0.05 ; * * p<0.01 ; * * * p<0.005$ 
Table 2 Characteristics of the headache and accompanying symptoms in the 37 stroke patients with headache

\begin{tabular}{lrc}
\hline & \multicolumn{2}{c}{ Patients, $\mathrm{n}(\%)$} \\
\hline Location & & \\
$\quad$ Anterior & 17 & $(45.9)$ \\
$\quad$ Posterior & 8 & $(21.6)$ \\
$\quad$ Diffuse & 12 & $(32.4)$ \\
Side & & \\
$\quad$ Unilateral (ipsilateral to stroke) & 8 & $(21.6)$ \\
$\quad$ Unilateral (contralateral to stroke) & 0 & $(0)$ \\
$\quad$ Unilateral alternating & 0 & $(0)$ \\
$\quad$ Bilateral & 29 & $(78.4)$ \\
Severity & & \\
$\quad$ Mild & 0 & $(0)$ \\
$\quad$ Moderate-severe & 37 & $(100.0)$ \\
Pain quality & & \\
$\quad$ Pulsating & 24 & $(64.9)$ \\
$\quad$ Bursting & 10 & $(27.0)$ \\
$\quad$ Compressing & 3 & $(8.1)$ \\
Accompanying symptoms & & \\
$\quad$ Nausea & 19 & $(51.4)$ \\
$\quad$ Vomiting & 4 & $(10.8)$ \\
Photophobia & 19 & $(51.4)$ \\
$\quad$ Phonophobia & 10 & $(27.0)$ \\
$\quad$ None & 10 & $(27.0)$ \\
\hline
\end{tabular}

hemorrhagic and ischemic strokes separately. Thirty (17 women) of the 37 patients had a history of headache (according to IHS criteria [9], 21 (57\%) patients had tension-type headache, 8 had migraine and 1 had another type of headache); of these, 16 patients had headache during stroke. No relationship between the characteristics of strokeinduced headache and the type of previous headache was found in the patients with a history of headache.

In $17(21.0 \%)$ of the 81 patients with ischemic stroke or TIA, CT showed no abnormality. In the other patients, no relationship was found between the size of the lesion detected by CT and the presence of headache: $24.1 \%$ of patients with headache had an ASPECT score $<7$ on CT scan in comparison to $32.8 \%$ of patients without headache. Eleven patients $(47.8 \%)$ with ischemic stroke and headache had lacunar infarcts in comparison to $24(51.1 \%)$ with ischemic stroke without headache.

\section{Discussion}

Our study confirms that headache is a relatively common phenomenon in cerebrovascular disease. Headache was present in more than one-third of 104 patients with acute stroke and was much more common among patients with cerebral hemorrhage than in patients with stroke or TIA. Fifty-two percent of the patients with cerebral hemorrhage had headache during stroke; these results are similar to those of a previous report [10].

Headache was much more common among patients with cerebrovascular disease in the posterior circulation than in patients in whom the anterior circulation was involved. This can be attributed to the richer innervation of the vessels by nociceptive afferents in the posterior circulation than in the anterior circulation as suggested by several authors $[1,11$, $12,15]$.

In patients with unilateral cerebral lesions and unilateral headache, the headache in most cases was ipsilateral to the cerebral lesion. This observation suggests that headache is linked to an activation of the ipsilateral nociceptive cerebral afferents. Diffuse headache was present in $32.4 \%$ of the patients and bilateral in $78.4 \%$. The organization of the trigeminovascular system may help to explain why headache, like other visceral pains, cannot be properly located or is bilateral, following an intracranial focal lesion. This may be due to the fact that the receptive fields of the trigeminal neurons are wide and frequently include bilateral intracranial structures [13]. Headache during stroke seems to be induced through the activation of the trigeminovascular system [11]. It is not clear which factors contribute to the activation of the trigeminal system in causing headache. They may include substances produced from endothelium of the cerebrovasculature or from damaged brain tissue such as bradykinins, nitric oxide or vasoactive peptides released from trigeminal endings such as calcitonin gene-related peptides and substance P. They can contribute to increase the nociceptive input to the brain resulting in head pain. If this peripheral mechanism is preferentially taken into account to explain pain in the cerebrovascular diseases, other mechanisms could be implicated, such as spreading depression in the vicinity of the ischemic lesion area, which can putatively intervene in triggering and maintaining head pain.

A history of headache was associated with the presence of stroke-associated headache. Data from the literature provide conflicting information in this respect $[1,2,12]$, but recent studies indicate that in acute stroke, headache is often a reactivation of the patient's usual type of headache and that ischemia can trigger a flurry of migraine episodes [14]. In this study, $56 \%$ of patients with a history of headache had tension-type headache. Previous reports [1, 15] suggest that headache during stroke may be caused by a release of vasoactive substances (similar in migraine attacks) in the trigeminovascular system, but the same release of these vasoactive substances seems to have an important role in the multifactorial pathogenesis of tension-type headache [16].

No relationship was found between the size of the lesion detected by CT scan and the presence of headache. Also, lacunar infarcts were found in $47.8 \%$ of patients with 
ischemic stroke and headache. This suggests that ischemia and parenchymatous damage per se are not the main factors inducing headache. Other authors [12] explained this result with the notion that mechanisms at the surface of the brain (for example, the vasculature) may play a role in pain genesis.

In our study we found that headache started before stroke (sentinel headache) in $40.5 \%$ of the study subjects. This observation is in accordance with previous studies [2, $3,12]$ and indicates that headache in stroke often has an organic rather than a psychogenic etiology. Stroke could be a result of a long pathological vascular process, in which headache merely serves as a warning sign of ischemic stroke.

The limitation of our study, considering the subgroups separately (patients with TIA, ischemic or hemorrhagic stroke), is the low number of the patients enrolled which does not permit an accurate analysis.

In conclusion, headache was present in $35.6 \%$ of the patients with cerebrovascular disease and was more common in hemorrhagic stroke compared to ischemic stroke or TIA. Headache was much more common among patients with cerebrovascular disease in the posterior circulation than in patients in whom the anterior circulation was involved.

\section{References}

1. Edmeads J (1979) The headache of ischemic cerebrovascular disease. Headache 19(6):345-349

2. Portenoy RK, Abissi CJ, Lipton RB, Berger AR, Mebler MF, Baglivo J, Solomon S (1984) Headache in cerebrovascular disease. Stroke 15(6):1009-1012

3. Gorelick PB, Hier DB, Caplan LR, Langenberg P (1986) Headache in acute cerebrovascular disease. Neurology 36(11):1445-1450

4. Koudstaal PJ, van Gijn J, Kappelle LJ (1991) Headache in transient or permanent cerebral ischemia. Dutch TIA Study Group. Stroke 22(6):754-759

5. Arboix A, Massons J, Oliveres M, Arribas MP, Titus F (1994) Headache in acute cerebrovascular disease: a prospective clinical study in 240 patients. Cephalalgia 14(1):37-40

6. Paciaroni M, Parnetti L, Sarchielli P, Gallai V (2001) Headache associated with acute ischemic stroke. J Headache Pain 2(1):25-29
7. Blanchard EB, Andrasik F (1985) Management of chronic headaches, a psychological approach. Exeter Pergamon Press

8. Barber PA, Demchuk AM, Zhang J, Buchan AM (2000) Validity and reliability of a quantitative computed tomography score in predicting outcome of hyperacute stroke before thrombolytic therapy. ASPECTS Study Group. Alberta Stroke Programme Early CT Score. Lancet 355(9216):1670-1 674

9. - (1988) Classification and diagnostic criteria for headache disorders, cranial neuralgias and facial pain. Headache Classification Committee of the International Headache Society. Cephalalgia 8[Suppl 7]:1-96

10. Melo TP, Pinto AN, Ferro JM (1996) Headache in intracerebral hematomas. Neurology 47(2):494-500

11. Moskowitz MA (1984) The neurobiology of vascular head pain. Ann Neurol 16(2):157-168
12. Vestergaard K, Andersen G, Nielsen Ml, Jensen TS (1993) Headache in stroke. Stroke 24(11):1621-1624

13. Moskowitz MA (1993) The trigeminovascular system. In: Olesen J, TfeltHansen P, Welch KMA (eds) The headaches. Raven, New York, pp 97-104

14. Olesen J, Friberg L, Olsen TS, Andersen AR, Lassen NA, Hansen PE, Karle A (1993) lschaemia-induced (symptomatic) migraine attacks may be more frequent than migraineinduced ischaemic insults. Brain 116(Pt 1):187-202

15. Edmeads J (1983) Complicated migraine and headache in cerebrovascular disease. Neurol Clin 1:385-397

16. Jensen R (1999) The tension-type headache alternative. Peripheral pathophysiological mechanisms. Cephalalgia 19[Suppl 25]:9-10 